\title{
Preoperative Assessment of Coronary Arteries by Cardiac Computed Tomography in Patients with Lung Cancer
}

\author{
Fan Zhang ${ }^{1}$ jing Chen ${ }^{2}$ Zhi-Gang Yang ${ }^{3}$ Han Liu $^{1}$ \\ ${ }^{1}$ Department of Gynaecology and Ostetrics, The Affiliated Hospital of \\ Southwest Medical University, Luzhou, China \\ 2 Department of Radiology, the Affiliated Hospital of Southwest \\ Medical University, Luzhou, Sichuan, China \\ ${ }^{3}$ Department of Radiology, West China Hospital of Sichuan \\ University, Chengdu, China
}

Thorac Cardiovasc Surg 2020;68:169-175.

Address for correspondence Jing Chen, MD, Department of Radiology, the Affiliated Hospital of Southwest Medical University, 25\# Tai Ping Street, Luzhou, Sichuan 646099, China (e-mail: yzqdcj@126.com).

\begin{abstract}
Keywords

- coronary artery disease

- lung resection

- non-small cell lung cancer

- computed tomography

Background To retrospectively evaluate characteristics of coronary artery disease $(C A D)$ in patients undergoing lung resection for cancer by using dual-source computed tomography (DSCT), thus increasing our understanding of perioperative evaluation. Methods DSCT coronary angiography was performed for perioperative evaluation in 145 patients with non-small cell lung cancer (NSCLC) due to suspected CAD. The imaging characteristics of CAD including extent, distribution and types of plaques, and luminal stenosis and congenial anomalous including origin of coronary arteries and myocardial bridge (MB) were evaluated and compared by sex, smoking behavior, and pathological types.

Results In total, coronary artery plaques were observed in 130 (89.7\%) patients. A total of 205 coronary vessels $(1.7 \pm 1.3$ per patient $)$ and 278 segments $(2.4 \pm 2.3$ per patient) were found to have plaques, respectively. The most frequently involved segment were the left anterior descending (LAD) artery (45.4\%) and its proximal segment $(24.1 \%)(p<0.05)$. Mild narrowing $(61.7 \%)$ and calcified plaques $(52.9 \%)$ were most found (all $p<0.001$ ). Types of plaques, luminal narrowing and extent were not significantly different by sex, smoking behavior, or pathological type. Anomalous origination of the right coronary ostium from left sinus was observed in $0.7 \%$ of patients. MB was observed in $16.6 \%$ of patients.

Conclusion Dual-source $C T$ is a useful preoperative noninvasive test for CAD in patients planning to undergo lung resection for cancer.
\end{abstract}

\section{Introduction}

It is relatively common that lung cancer and coronary artery disease (CAD) occur simultaneously for same risk factors, such as aging and smoking. In addition, some cardiac drugs were proposed to have potential carcinogenic effect. ${ }^{1}$ The feasibility and timing of operation for non-small cell lung cancer (NSCLC) are associated with the history of CAD

received

June 3, 2018

accepted after revision

July 4,2018

published online

August 16, 2018

because it may increase perioperative morbidity. ${ }^{2}$ In addition, CAD can limit or restrict operations for cancer, and cancer can limit the treatment of CAD. Studies have shown that preoperative noninvasive testing could provide risk stratification for evaluating perioperative risk of cardiovascular events. ${ }^{3}$ Commonly used tools for noninvasive assessment of CAD include multislice computed tomography (CT), especially cardiac CT. It can accurately identify plaque

(c) 2020 Georg Thieme Verlag KG Stuttgart · New York
DOI https://doi.org/ 10.1055/s-0038-1668166. ISSN 0171-6425. 
composition and depict the degrees of intracavitary stenosis. It can also easily identify outward remodeling without luminal narrowing that lesions sometimes show, an effect that cannot be seen with invasive coronary angiography., ${ }^{4,5}$ Thus, we retrospectively evaluated characteristics of CAD by using cardiac CT for patients planning to undergo lung resection for cancer, thus increasing our understanding of perioperative management.

\section{Materials and Methods}

\section{Study Population}

According to the Declaration of Helsinki (2000 EDITION), the Institutional Review Board (IRB) in our hospital approved the application for exemption of patients' informed consents because of its retrospective design.

From January 2013 to January 2016, 160 patients with NSCLC who underwent coronary dual-source computed tomography (DSCT) angiography (DSCTA) examination for suspected CAD as preoperative assessment of elective surgery were enrolled in this study. In stages I and II patients who functionally fit with, according to current guideline for therapy of $\mathrm{NSCLC}^{6}$ and the American Joint Committee on Cancer/Union for International Cancer Control (AJCC/UICC)TNM classification and stage grouping, ${ }^{7}$ surgical resection (lobectomy/pneumonectomy with lymphadenectomy) is recommended. Exclusion criteria for CT scan included patients with a left ventricular ejection fraction of less than $40 \%$, renal dysfunction (glomerular filtration rate $<30 \mathrm{~mL} / \mathrm{min} / 1.7 \mathrm{~m}^{2}$ ), severe heart failure, known allergy to iodine-based contrast medium, and inadequate image quality for imaging analysis. Finally, 145 patients with NSCLC were recruited. Baseline characteristics of patients with NSCLC are listed in - Table 1.

\section{DSCT Technique}

DSCT (Somatom Definition, Siemens Medical Solutions, Germany) scanning were applied for all patients with a retrospective electrocardiograph (ECG)-gated mode. Scanning was performed in a craniocaudal direction with the following acquisition parameters: collimation was $64 \times 0.6 \mathrm{~mm}$, pitch 0.2 to 0.5 (selected according to heart rate), gantry rotation time $3.30 \mathrm{~s}$, tube current (body mass index [BMI] $<25 \mathrm{~kg} / \mathrm{m}^{2}$, $220 \mathrm{~mA}$ per rotation; $\mathrm{BMI} \geq 25 \mathrm{~kg} / \mathrm{m}^{2}, 330 \mathrm{~mA}$ per rotation), and weight-dependent tube potential (weight $\geq 85 \mathrm{~kg}, 120 \mathrm{kV}$ for each tube; weight $<85 \mathrm{~kg}, 100 \mathrm{kV}$ for each tube). The nonionic contrast agent (iopamidol, $370 \mathrm{mg} / \mathrm{mL}$; Bracco Sine Pharmaceutical Corp. Ltd., Shanghai, China) with only 60 to $80 \mathrm{~mL}$ was injected into an antecubital vein at a flow rate of $5.0 \mathrm{~mL} / \mathrm{s}$, followed by $20 \mathrm{~mL}$ of a saline solution at the same flow rate. Once the interest region on the left atrium reached the contrast concentration threshold of 100-Hounsfield units, it was automatically initiated for the image acquisition along after a delay of 5 seconds.

\section{Imaging Analysis}

Two experienced radiologists independently reviewed each CT scan on a dedicated workstation (Leonardo, Siemens
Table 1 Baseline characteristics of patients

\begin{tabular}{|l|l|}
\hline Characteristic & Value \\
\hline Age, y & $70.4 \pm 6.4$ \\
\hline Male gender (male:female) & $1.5: 1$ \\
\hline Weight (kg) & $60.8 \pm 10.5$ \\
\hline BMI & $23.1 \pm 3.8$ \\
\hline Current Smoking & $43.4 \%$ \\
\hline Hypertension & $38.6 \%$ \\
\hline Diabetes mellitus & $12.4 \%$ \\
\hline LVEF & $58.3 \% \pm 10.2 \%$ \\
\hline Lung cancer & \\
\hline Adenocarcinoma & 115 \\
\hline Squamous cell carcinoma & 30 \\
\hline Lung surgery & 144 \\
\hline Lobectomy & 47 \\
\hline Right upper lobe & 9 \\
\hline Right middle lobe & 30 \\
\hline Right lower lobe & 28 \\
\hline Left upper lobe & 20 \\
\hline Left lower lobe & 10 \\
\hline Two lobes & 16 \\
\hline Pneumonectomy & 4 \\
\hline Wedge resections & \\
\hline Sleeve lobectomy & \\
\hline Concomitant pathology & \\
\hline Heart valvular diseases & 12 \\
\hline Carotid stenosis & \\
\hline Aortal atherosclerosis & \\
\hline
\end{tabular}

Abbreviations: BMI, body mass index; LVEF, left ventricular ejection fraction, measured by echocardiography.

Medical Systems), blinding to the final diagnosis. Any disagreement of anatomical variants and measurements was negotiated until a consensus decision was reached. Maximum intensity projection, curvature plane reconstruction, multiplanar reconstruction, and volume reconstruction were used for observing coronary artery plaques.

Coronary vessels were classified into four branches: right coronary artery (RCA), left main (LM), left circumflex (LCX), and left anterior descending (LAD). In accordance with the classification standard of the American Heart Association, coronary arteries were assessed by dividing them into 15 segments. ${ }^{8}$ Anomalous origins of coronary arteries, myocardial bridges $(\mathrm{MB})$, number of involved coronary branches and segments, number and types of plaques, and degree of luminal narrowing by plaques were assessed. The segment plaque chosen for the analysis was the one at a site within the most severely stenotic vessel. Plaques were divided into three types: noncalcified plaque (lesions with lower CT 
attenuation than the contrast-enhanced lumen without any calcification), calcified plaque (lesions with a higher CT density than the contrast-enhanced lumen), and mixed plaques (calcified and noncalcified components in a single plaque). ${ }^{9}$ Coronary artery stenoses were classified into significant stenoses and nonsignificant stenoses by a $50 \%$ threshold of luminal narrowing. Moreover, the stenoses were further divided to normal appearing (degree of stenosis, $<25 \%$ ), mild (degree of stenosis, 25-49\%), moderate (degree of stenosis, 50-74\%), and severe (degree of stenosis, $\geq 75 \%$ ) narrowing on the basis of two orthogonal views. ${ }^{10}$ It was defined MB was a tunnel formed by superficial fibers of the myocardium passing through the outer aspect of a coronary artery.

\section{Statistical Analysis}

Dedicated SPSS software (Version 16; Chicago, Illinois, United States) were applied for all statistical analyses. Continuous data were expressed as mean values and corresponding standard deviations, and dichotomous data were recorded as numbers and percentages. Comparisons of the prevalence of involved vessels between multi and singlevessel diseases, different types of plaques, degree of stenosis and plaque distributions among different vessels, and segments were performed using a chi-square test or Fisher's exact test. Interobserver variation was evaluated by kappa statistic. Comparisons of the manifestations of CAD between patients of different sexes, smoking behavior, and pathological types were performed using independent sample $t$ tests. Differences with $p<0.05$ were considered to be statistically significant.

\section{Results}

\section{Preoperative Baseline Characteristics}

Cardiac CT scanning was successfully performed in all 145 patients, whose age ranged from 41 to 83 years (mean $70 \pm 6$ years). Baseline characteristics of subjects in our study are shown in - Table 1. Of the 145 patients, 7 with severe stenosis underwent invasive coronary angiography, and 3 of whom underwent coronary interventions according to the guidelines of the American College of Cardiology. No patients had angina or postoperative ischemic myocardial infarctions during the 30 days after surgery. These patients had a two-staged operation, first a percutaneous transluminal coronary angioplasty (PTCA) procedure ( - Fig. 1A and B), followed by a lung resection 1 to 2 weeks later.

\section{Coronary Anomalies}

Anomalous origination for the right coronary ostium from the left sinus (-Fig. 1C) was observed in $0.7 \%(1 / 145)$ of patients. An MB ( - Fig. 1D) was observed in 16.6\% (24/145) of patients. The most common involved segment for MB was the distal segment of the $\operatorname{LAD}(18 / 2175,0.8 \%, p<0.05)$.

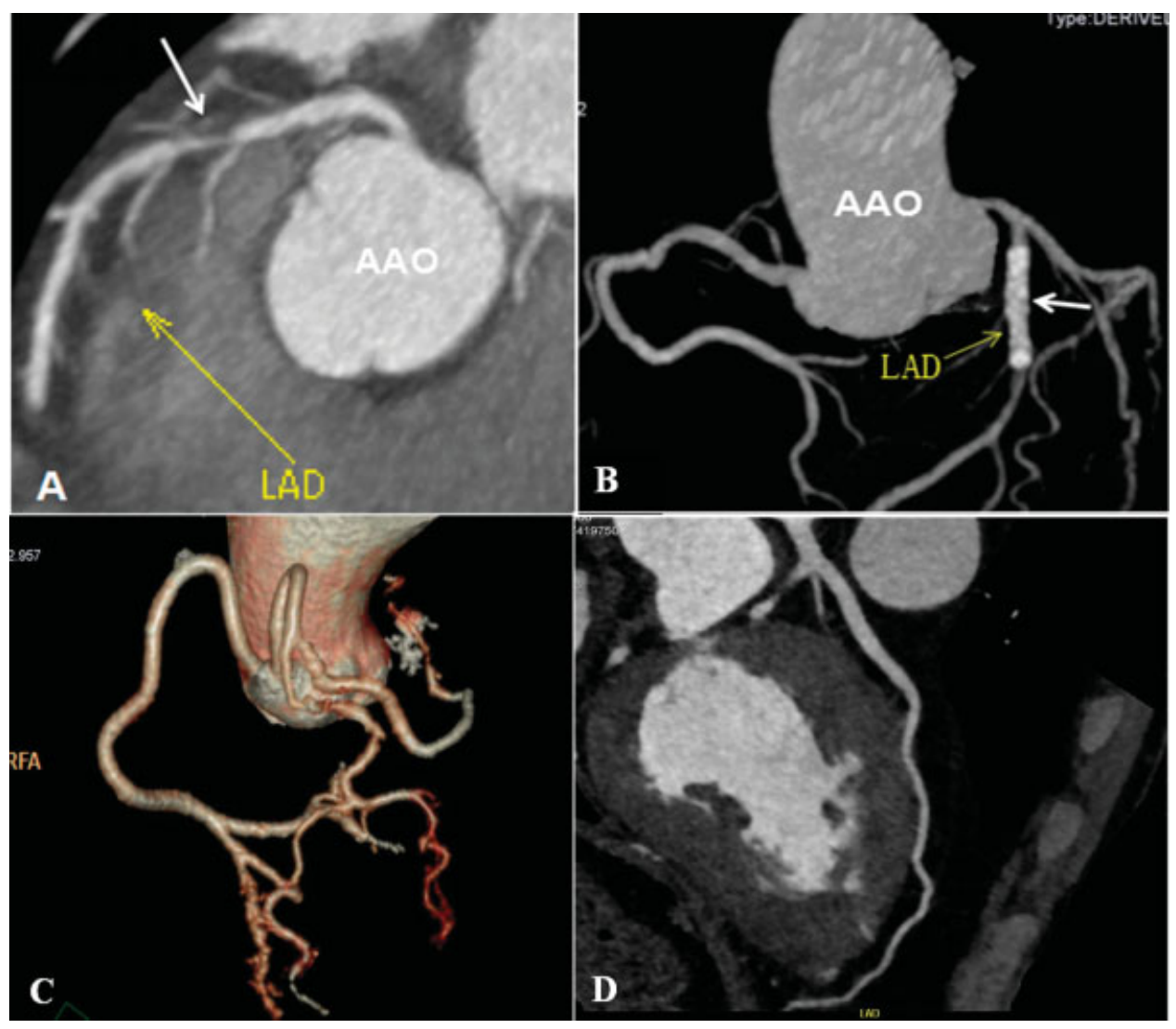

Fig. 1 The curvature plane reconstruction image shows serve stenosis (yellow arrow) caused by a filling defect (A). The coronary artery stent (arrow) is implanted in the left anterior descending coronary artery (B). The volume rendering image (C) shows anomalous origination of the right coronary ostium from the left sinus. The curvature plane reconstruction image (D) shows a myocardial bridge (arrow). 


\section{Plaque Distribution and Extent}

DSCT scanning revealed $130(89.7 \%)$ subjects with coronary artery plaques and 15 (10.3\%) patients without plaques. Coronary artery plaques were detected in 205 coronary vessels ( $1.7 \pm 1.3$ per patient; range, $0-4)$ and 278 segments $(2.4 \pm 2.3$ per patient; range, $0-10)$. There was no significant difference in the number of patients with vessels between multi-vessel $(\geq 2)$ and single-vessel disease (72/130 [55.4\%] versus 58/130 [44.6\%], $p>0.05$ ). Regarding plaque distribution, the most frequent major involved vessel with plaques was the LAD artery $(93 / 205,45.4 \%$, all $p<0.001)$, followed by the RCA $(54 / 205,26.3 \%)$, the LCX $(41 / 205,20 \%)$, and the LM artery $(17 / 205,8.3 \%)$. The most commonly involved coronary segment was the proximal segment of the LAD $(67 / 278,24.1 \%, p<0.05)$. The kappa value for interobserver variation with coronary measurements was 0.79 .

\section{Plaque Composition and Luminal Narrowing}

Composition of plaques and degree of stenosis are measured and summarized in -Table 2. In general, 295 plaques $(2.3 \pm 2.0$ per patient; range, $1-12)$ were found, of which 156 (52.9\%) were calcified (-Fig. 2A), 83 (28.1\%) were mixed (-Fig. 2B), and $56(19.0 \%)$ were non-calcified (-Fig. 2C) $(p<0.001)$. Of the grading of stenosis, mild stenosis $(61.7 \%)$ was the most common compared with the others (11.2\%, 20.7\%, and $6.4 \%$ for normal appearing, moderate stenosis, and severe stenosis, respectively, all $p<0.001)$. A total of $215(72.9 \%)$ patients showed nonobstructive stenosis, and 80 (27.1\%) showed obstructive stenosis $(p<0.001)$. The kappa value for interobserver variation with coronary measurements was 0.79 .

\section{Comparison of CT Findings of CAD among Genders, Smoking Behaviors, and Pathological Types}

Comparisons of the extent of involved coronary arteries, types of plaques, and grading of luminal stenosis on CT images between genders, smoking behaviors, and pathological types are analyzed and shown in - Table 3. Men had

Table 2 Involved manifestation of coronary artery in patients

\begin{tabular}{|c|c|}
\hline & Total value \\
\hline \multicolumn{2}{|l|}{ Types of plaque } \\
\hline Calcified plaque & $156(52.9)$ \\
\hline Mixed plaque & $83(28.1)$ \\
\hline Noncalcified plaque & $56(19.0)$ \\
\hline \multicolumn{2}{|l|}{ Grading of stenosis } \\
\hline Normal appearing & $33(11.2)$ \\
\hline Mild narrowing & $182(61.7)$ \\
\hline Moderate narrowing & $61(20.7)$ \\
\hline Severe narrowing & $19(6.4)$ \\
\hline Nonobstructive stenosis & $215(72.9)$ \\
\hline Obstructive stenosis & $80(27.1)$ \\
\hline
\end{tabular}

Results are given as $n$ (percentage). Nonobstructive stenosis includes normal appearing and mild narrowing. Obstructive stenosis includes moderate and severe narrowing. more involved coronary vessels and segments compared with women $(p<0.05)$. In addition, more plaques were found in men, especially calcified plaques $(p<0.05)$. The plaques in men commonly resulted in mild narrowing and non-obstructive stenosis of the coronary lumen. Smoking patients had more involved coronary vessels compared with nonsmoking patients, commonly leading to mild narrowing and nonobstructive stenosis of the coronary lumen. There was no significant difference for CT findings of CAD among pathological types of NSCLC in all aspects, except that patients with adenocarcinoma had more mixed plaques $(p<0.05)(-$ Fig. 3).

\section{Discussion}

In the case of NSCLC, patients concomitant with CAD during preoperative evaluation for lung resection show increased operative morbidity. ${ }^{2,11}$ Meanwhile, the surgeon faces the issue of choosing the timing of a surgical approach for both lung and heart, whether it be concomitantly or in a staged way. These issues indicate that the presence of CAD needs to be screened before elective lung resection. As a non-invasive assessment tool for CAD and pulmonary vessel anatomy, DSCTA exhibits superiority in predicting risk stratification and postoperative cardiovascular events for noncardiac surgeries. ${ }^{12}$ Therefore, careful preoperative evaluation of the coronary artery with DSCT in patients undergoing lung resection is imperative, and it can help the clinician to establish a better treatment strategy.

Our results showed $\mathrm{MB}$ commonly occurred in the distal segment of the LAD, which is consistent with the study. ${ }^{13} \mathrm{MB}$ is generally seen to a benign condition. However, anatomical characters of MB, especially its thickness and length, are associated with coronary atherosclerosis development and may induce myocardial infarction. ${ }^{14}$ Therefore, knowledge of anatomic properties may contribute to identify low- and high-risk patients before surgery for better intervention measures. DSCT can accomplish this.

Different hemodynamics may cause different susceptibilities of each coronary vessel and segment to atherosclerosis. ${ }^{15}$ Our results revealed that the proximal segment of the LAD artery was the most frequent major involved vessel with plaques, which is consistent with findings in the general population. ${ }^{16}$ Although its plaques may not lead to significant luminal narrowing over a short time due to its large caliber, the cardiovascular event would be serious once the lumen was occluded.

The incidence of adverse future event rate in patients with any coronary plaque was significantly higher than those with a normal MDCT scan. ${ }^{17}$ The fact that plaque composition is associated with the clinical consequences of CAD may be an explanation for this. Noncalcified plaques are more likely to cause acute ischemic coronary syndromes due to their unstable characteristics. ${ }^{18}$ Patients with calcified plaques may have better long-term clinical outcomes than those with noncalcified and mixed plaques. ${ }^{19}$ Therefore, it is imperative to timely evaluate and treat any plaque. 


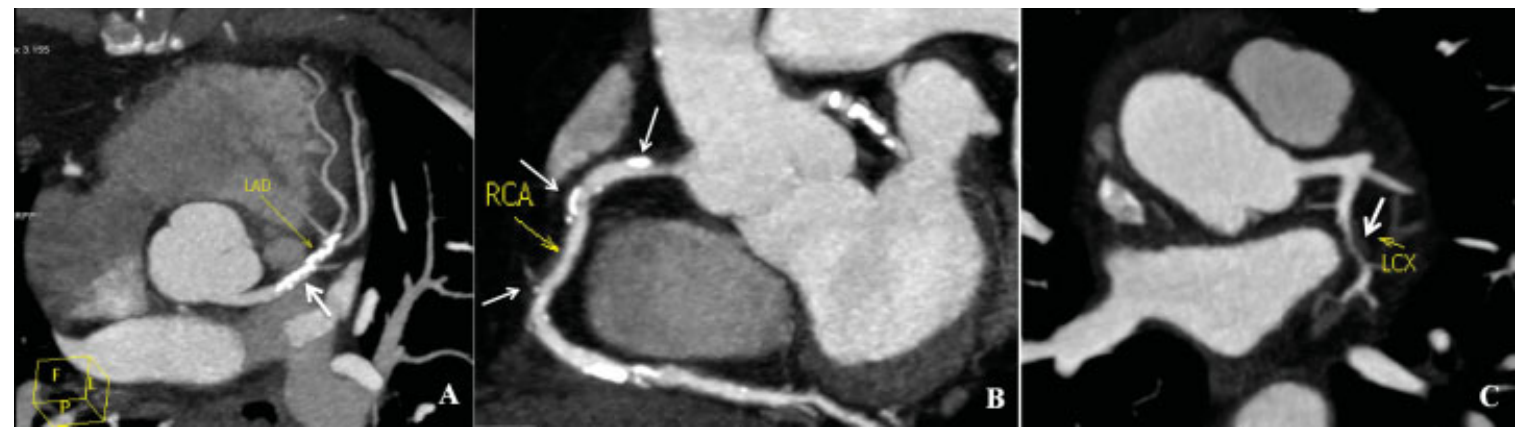

Fig. 2 The curvature plane reconstruction image shows that the density of calcified plaques (arrow) is significantly higher than the contrastenhanced lumen (A). The curvature plane reconstruction image shows many noncalcified plaques and calcified plaques mixed together in the right coronary artery (arrows). Other findings: calcified plaques in the left coronary artery (B). The curvature plane reconstruction image shows a filling defect and moderate stenosis in the left circumflex coronary artery (arrow) (C). AAO, ascending aorta; LAD, left anterior descending coronary artery; LCX, left circumflex coronary artery; RCA, right coronary artery.

In our study, men had more involved coronary vessels and segments compared with women. More plaques were found in men, which is consistent with other findings. ${ }^{20}$ However, our findings are inconsistent for lumen stenosis. The plaques in men commonly resulted in only mild narrowing and nonobstructive stenosis of the coronary lumen. It is possible that these results are related to other risk factors for CAD in our study, such as older age and diabetes, which were more common for women. Therefore, the coronary artery for women was less likely to develop less severe stenosis.

Smoking has also been causally associated with CAD. ${ }^{21}$ In our study, smoking patients had more involved coronary

Table 3 Comparison of coronary artery diseases between different sexes, smoking conditions, and pathological types

\begin{tabular}{|c|c|c|c|c|c|c|c|c|c|}
\hline & $\begin{array}{l}\text { Female } \\
(n=57)\end{array}$ & $\begin{array}{l}\text { Male } \\
(n=88)\end{array}$ & $p$-Value & $\begin{array}{l}\text { Smoking } \\
(n=63)\end{array}$ & $\begin{array}{l}\text { Non- } \\
\text { smoking } \\
(n=82)\end{array}$ & $p$-Value & Adenocarcinoma & $\begin{array}{l}\text { Squamous } \\
\text { cell } \\
\text { carcinoma }\end{array}$ & $p$-Value \\
\hline \multicolumn{10}{|l|}{ Extent } \\
\hline $\begin{array}{l}\text { Diseased } \\
\text { vessels }\end{array}$ & $1.0 \pm 1.0$ & $1.7 \pm 1.3$ & 0.001 & $1.6 \pm 1.3$ & $1.1 \pm 1.0$ & 0.032 & $1.3 \pm 1.2$ & $1.8 \pm 1.2$ & 0.137 \\
\hline $\begin{array}{l}\text { Diseased } \\
\text { segments }\end{array}$ & $1.4 \pm 1.5$ & $2.3 \pm 2.2$ & 0.003 & $2.1 \pm 2.0$ & $1.4 \pm 1.6$ & 0.126 & $1.8 \pm 1.9$ & $2.3 \pm 1.8$ & 0.235 \\
\hline \multicolumn{10}{|l|}{ Types of plaque } \\
\hline Total plaques & $1.6 \pm 1.6$ & $2.5 \pm 2.1$ & 0.013 & $1.9 \pm 1.3$ & $1.6 \pm 0.8$ & 0.135 & $1.9 \pm 1.3$ & $1.8 \pm 1.2$ & 0.534 \\
\hline $\begin{array}{l}\text { Calcified } \\
\text { plaque }\end{array}$ & $1.7 \pm 0.9$ & $2.5 \pm 1.7$ & 0.012 & $2.2 \pm 1.6$ & $1.8 \pm 1.0$ & 0.315 & $2.2 \pm 1.6$ & $2.1 \pm 1.6$ & 0.805 \\
\hline Mixed plaque & $1.4 \pm 0.7$ & $1.8 \pm 1.2$ & 0.280 & $1.7 \pm 1.1$ & $1.5 \pm 0.7$ & 0.669 & $1.8 \pm 1.0$ & $1.5 \pm 0.9$ & 0.012 \\
\hline $\begin{array}{l}\text { Non-calcified } \\
\text { plaque }\end{array}$ & $1.3 \pm 1.0$ & $1.7 \pm 0.8$ & 0.189 & $1.7 \pm 0.7$ & $1.2 \pm 0.4$ & 0.245 & $1.5 \pm 0.8$ & $1.5 \pm 0.5$ & 0.915 \\
\hline \multicolumn{10}{|c|}{ Grading of stenosis } \\
\hline $\begin{array}{l}\text { Normal } \\
\text { appearing }\end{array}$ & $1.1 \pm 0.3$ & $1.2 \pm 0.4$ & 0.472 & $1.1 \pm 0.4$ & $1.2 \pm 0.4$ & 0.622 & $1.1 \pm 0.4$ & $1.3 \pm 0.5$ & 0.547 \\
\hline $\begin{array}{l}\text { Mild } \\
\text { narrowing }\end{array}$ & $1.4 \pm 0.6$ & $2.1 \pm 1.3$ & 0.000 & $2.8 \pm 1.6$ & $1.5 \pm 0.7$ & 0.002 & $1.8 \pm 1.2$ & $2.1 \pm 1.1$ & 0.395 \\
\hline $\begin{array}{l}\text { Moderate } \\
\text { narrowing }\end{array}$ & $1.8 \pm 1.3$ & $1.4 \pm 0.7$ & 0.516 & $1.6 \pm 1.0$ & $1.8 \pm 1.2$ & 0.533 & $1.5 \pm 0.8$ & $1.4 \pm 0.8$ & 0.840 \\
\hline $\begin{array}{l}\text { Severe } \\
\text { narrowing }\end{array}$ & $1.5 \pm 0.7$ & $1.1 \pm 0.4$ & 0.345 & $1.2 \pm 0.4$ & $1.3 \pm 0.5$ & 0.662 & $1.2 \pm 0.5$ & $1.1 \pm 0.4$ & 0.635 \\
\hline $\begin{array}{l}\text { Nonobstructive } \\
\text { stenosis }\end{array}$ & $1.3 \pm 0.5$ & $1.8 \pm 1.1$ & 0.001 & $2.2 \pm 1.5$ & $1.4 \pm 0.7$ & 0.010 & $1.6 \pm 1.1$ & $1.9 \pm 1.0$ & 0.326 \\
\hline $\begin{array}{l}\text { Obstructive } \\
\text { stenosis }\end{array}$ & $1.7 \pm 1.1$ & $1.3 \pm 0.6$ & 0.210 & $1.5 \pm 0.9$ & $1.6 \pm 0.9$ & 0.800 & $1.4 \pm 0.8$ & $1.3 \pm 0.6$ & 0.523 \\
\hline
\end{tabular}

Results are given as mean \pm standard deviation. Non-obstructive stenosis includes normal appearing and mild narrowing. Obstructive stenosis includes moderate and severe narrowing. Bold values represent the significant $p$ values. 


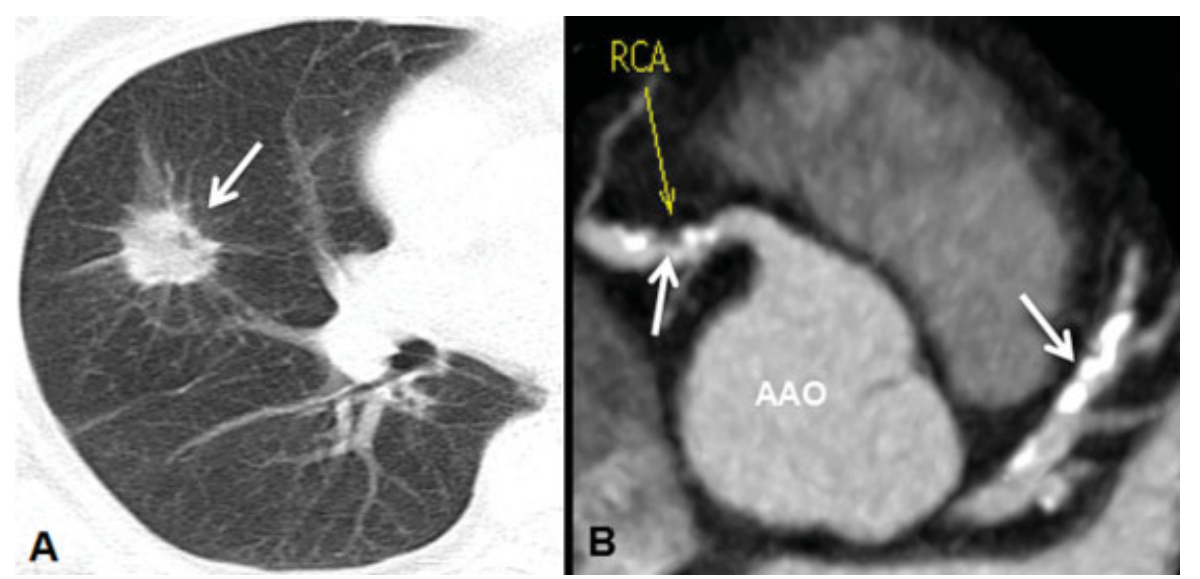

Fig. 3 Coronary plaques in patients with lung cancer. A mass $(3.5 \times 4.9 \mathrm{~cm})($ arrow) that proved to be a well-differentiated adenocarcinoma in a 64-year-old smoking man is in the right middle lobe (A). Patients with adenocarcinomas had more mixed plaques (B) (arrow) compared with those with squamous cell carcinoma. AAO, ascending aorta; LAD, left anterior descending coronary artery; LCX, left circumflex coronary artery; RCA, right coronary artery.

vessels compared with nonsmoking patients. The mechanisms of atherosclerosis induced by smoking include a decreased availability of nitric oxide (NO) resulting in vasomotor and endothelial dysfunction, an increase in proinflammatory cytokines enhance leukocyte recruitment, leukocyte-endothelial cell interactions, activation of proatherogenic substances, and oxidative modification of lipids. ${ }^{22}$ There was no significant difference for CT findings of CAD among pathological types of NSCLC in all aspects, except that patients with adenocarcinoma had more mixed plaques; it is unclear why, and additional study is necessary.

In the study, the percentage of severe luminal narrowing was $5 \%$ in patients scheduled for lung resection. It is slightly lower than that in previous study ${ }^{23}$ for possibly reason of small number of patients. Severe stenosis was considered as a significant indication for poor prognosis and an indicator of coronary revascularization; ${ }^{24}$ hence, these patients identified by DSCTA should deserve increased attention. Seven patients with severe stenosis found by DSCTA adopted invasive coronary angiography, and three met the indications for further coronary intervention. These patients face a difficult choice of undergoing concomitant or staged operations on both the heart and lungs.

There were many studies about the feasibility of concomitant operations, but were controversial. ${ }^{25,26}$ Although this approach is attractive because it can quickly treat both diseases with fewer resource expenditures, increased concerns associated with the potential bleeding complications from the heparinization and to possible infections and spread of cancer from the cellular and humoral immunosuppressive effects of cardiopulmonary bypass are used as an argument against this approach. Off-pump coronary artery revascularization may reduce the incidence of complications, ${ }^{27}$ but Schoenmakers et al found no significant differences between on- or off-pump techniques in relation to complications. ${ }^{26}$ For a staged operation with two surgical incisions (a thoracotomy and a sternotomy), there is also controversy as to which procedure should be performed first. ${ }^{28,29}$ Ambrogi et al considered that a vascular operation had a potential lower perioperative risk and relatively more priority for an early stage NSCLC with slow-growing for elderly patients and therefore it can be performed first. ${ }^{28}$ In our series, the three patients underwent the vascular procedure first. A lung resection is then suggested 4 to 6 weeks after open-heart procedure and 1 to 2 weeks after PTCA. $^{30}$ No patients had angina or postoperative ischemic myocardial infarctions during the 30 days after surgery. Thus, careful preoperative evaluation of the coronary artery with DSCT in patients undergoing lung resection can help to establish a better treatment strategy.

\section{Limitations}

This study does have some limitations. It was a cross-sectional study, and only patients with lung cancer coexisting with CADs were evaluated. Therefore, a selection bias existed. Moreover, a limitation for CT using is its radiation dose. However, radiation exposure from DSCTA is sharply reduced to $60 \%$ with attenuation-based online tube current modulation technique as compared with single-source CT $(\sim 8 \mathrm{mSv}){ }^{30}$

\section{Conclusion}

In conclusion, DSCTA provided the necessary preoperative information about arteriosclerotic lesions of the coronary arteries in patients with lung cancer before lung resection. It can help the surgeon to plan the management strategy and to stratify the risk of postoperative complications and mortality.

\section{Disclosures}

None.

\section{Funding Sources}

This research did not receive any specific grant from funding agencies in the public, commercial, or not-forprofit sectors. 


\section{Conflict of Interest}

None.

\section{References}

1 Reicher-Reiss H, Jonas M, Goldbourt U, Boyko V, Modan B. Selectively increased risk of cancer in men with coronary heart disease. Am J Cardiol 2001;87(04):459-462, A6

2 Stéphan F, Boucheseiche S, Hollande J, et al. Pulmonary complications following lung resection: a comprehensive analysis of incidence and possible risk factors. Chest 2000;118(05):1263-1270

3 Poldermans D, Bax JJ, Boersma E, et al; Task Force for Preoperative Cardiac Risk Assessment and Perioperative Cardiac Management in Non-cardiac Surgery of European Society of Cardiology (ESC); European Society of Anaesthesiology (ESA). Guidelines for preoperative cardiac risk assessment and perioperative cardiac management in non-cardiac surgery: The task force for preoperative cardiac risk assessment and perioperative cardiac management in non-cardiac surgery of the European Society of Cardiology (ESC) and endorsed by the European Society of Anaesthesiology (ESA). Eur J Anaesthesiol 2010;27(02):92-137

4 Budoff MJ, Achenbach S, Blumenthal RS, et al; American Heart Association Committee on Cardiovascular Imaging and Intervention; American Heart Association Council on Cardiovascular Radiology and Intervention; American Heart Association Committee on Cardiac Imaging, Council on Clinical Cardiology. Assessment of coronary artery disease by cardiac computed tomography: a scientific statement from the American Heart Association Committee on Cardiovascular Imaging and Intervention, Council on Cardiovascular Radiology and Intervention, and Committee on Cardiac Imaging, Council on Clinical Cardiology. Circulation 2006;114(16):1761-1791

5 Leber AW, Johnson T, Becker A, et al. Diagnostic accuracy of dualsource multi-slice CT-coronary angiography in patients with an intermediate pretest likelihood for coronary artery disease. Eur Heart J 2007;28(19):2354-2360

6 Felip E, Garrido P, Trigo JM, et al; Spanish Society of Medical Oncology. SEOM guidelines for the management of non-small-cell lung cancer (NSCLC). Clin Transl Oncol 2009;11(05):284-289

7 Goldstraw P, Crowley J, Chansky K, et al; International Association for the Study of Lung Cancer International Staging Committee; Participating Institutions. The IASLC Lung Cancer Staging Project: proposals for the revision of the TNM stage groupings in the forthcoming (seventh) edition of the TNM Classification of malignant tumours. J Thorac Oncol 2007;2(08):706-714

8 Austen WG, Edwards JE, Frye RL, et al. A reporting system on patients evaluated for coronary artery disease. Report of the Ad Hoc Committee for Grading of Coronary Artery Disease, Council on Cardiovascular Surgery, American Heart Association. Circulation 1975;51(4, Suppl):5-40

9 van Velzen JE, Schuijf JD, de Graaf FR, et al. Plaque type and composition as evaluated non-invasively by MSCT angiography and invasively by VH IVUS in relation to the degree of stenosis. Heart 2009;95(24):1990-1996

10 Hausleiter J, Meyer T, Hadamitzky M, Kastrati A, Martinoff S, Schömig A. Prevalence of noncalcified coronary plaques by 64slice computed tomography in patients with an intermediate risk for significant coronary artery disease. J Am Coll Cardiol 2006;48 (02):312-318

11 Kanzaki R, Inoue M, Minami M, et al. Outcomes of lung cancer surgery in patients with coronary artery disease: a decade of experience at a single institution. Surg Today 2017;47(01):27-34

12 Ahn J-H, Park JR, Min JH, et al. Risk stratification using computed tomography coronary angiography in patients undergoing intermediate-risk noncardiac surgery. J Am Coll Cardiol 2013;61(06):661-668

13 Leschka S, Koepfli P, Husmann L, et al. Myocardial bridging: depiction rate and morphology at CT coronary angiography- comparison with conventional coronary angiography. Radiology 2008;246(03):754-762

14 Ishikawa Y, Akasaka Y, Suzuki K, et al. Anatomic properties of myocardial bridge predisposing to myocardial infarction. Circulation 2009;120(05):376-383

15 Chatzizisis YS, Giannoglou GD, Parcharidis GE, Louridas GE. Is left coronary system more susceptible to atherosclerosis than right? A pathophysiological insight. Int J Cardiol 2007;116(01):7-13

16 Schmermund A, Baumgart D, Möhlenkamp S, et al. Natural history and topographic pattern of progression of coronary calcification in symptomatic patients: an electron-beam CT study. Arterioscler Thromb Vasc Biol 2001;21(03):421-426

17 Pundziute G, Schuijf JD, Jukema JW, et al. Prognostic value of multislice computed tomography coronary angiography in patients with known or suspected coronary artery disease. J Am Coll Cardiol 2007;49(01):62-70

18 Schuijf JD, Beck T, Burgstahler C, et al. Differences in plaque composition and distribution in stable coronary artery disease versus acute coronary syndromes; non-invasive evaluation with multi-slice computed tomography. Acute Card Care 2007;9(01):48-53

19 Ahmadi N, Nabavi V, Hajsadeghi F, et al. Mortality incidence of patients with non-obstructive coronary artery disease diagnosed by computed tomography angiography. Am J Cardiol 2011;107 (01):10-16

20 Chiha J, Mitchell P, Gopinath B, Plant AJH, Kovoor P, Thiagalingam A. Gender differences in the severity and extent of coronary artery disease. Int J Cardiol Heart Vasc 2015;8:161-166

21 Ezzati M, Henley SJ, Thun MJ, Lopez AD. Role of smoking in global and regional cardiovascular mortality. Circulation 2005;112(04): 489-497

22 Ambrose JA, Barua RS. The pathophysiology of cigarette smoking and cardiovascular disease: an update. J Am Coll Cardiol 2004;43 (10):1731-1737

23 Catalán P, Leta R, Hidalgo A, et al. Ruling out coronary artery disease with noninvasive coronary multidetector CT angiography before noncoronary cardiovascular surgery. Radiology 2011;258 (02):426-434

24 Levine GN, Bates ER, Blankenship JC, et al. ACCF; AHA; SCAI. 2011 ACCF/AHA/SCAI guideline for percutaneous coronary intervention: Executive summary: A report of the American College of Cardiology Foundation/American Heart Association Task Force on Practice Guidelines and the Society for Cardiovascular Angiography and Interventions. J Am Coll Cardiol 2011;(58):2550-2583

25 Tourmousoglou CE, Apostolakis E, Dougenis D. Simultaneous occurrence of coronary artery disease and lung cancer: what is the best surgical treatment strategy? Interact Cardiovasc Thorac Surg 2014;19(04):673-681

26 Schoenmakers MC, van Boven WJ, van den Bosch J, van Swieten HA. Comparison of on-pump or off-pump coronary artery revascularization with lung resection. Ann Thorac Surg 2007;84(02): 504-509

27 Mariani MA, van Boven WJ, Duurkens VAM, Ernst SM, van Swieten HA. Combined off-pump coronary surgery and right lung resections through midline sternotomy. Ann Thorac Surg 2001;71(04): 1343-1344

28 Ambrogi V, Pompeo E, Elia S, Pistolese GR, Mineo TC. The impact of cardiovascular comorbidity on the outcome of surgery for stage I and II non-small-cell lung cancer. Eur J Cardiothorac Surg 2003;23 (05):811-817

29 IVoets AJ, Sheik Joesoef KS, Van Teeffelen MEJM. Synchronously occurring lung cancer (stages I-II) and coronary artery disease: concomitant versus staged surgical approach. Eur J Cardiothorac Surg 1997; 12:713-717

30 Jongbloed MR, Dirksen MS, Bax JJ, et al. Atrial fibrillation: multidetector row CT of pulmonary vein anatomy prior to radiofrequency catheter ablation-initial experience. Radiology 2005;234 (03):702-709 